\title{
Model-Based Design of Integrative Energy Concepts for Building Quarters using Modelica
}

\author{
Dipl.-Ing. Torsten Schwan \\ Dipl.-Ing. René Unger \\ EA Systems Dresden GmbH, Königstr. 2, 01097 Dresden, Germany \\ torsten.schwan@ea-energie.de rene.unger@ea-energie.de \\ Dr.-Ing. Christian Lerche \\ Ingenieurbüro Dr. Lerche, Lugstr. 5, 01796 Pirna, Germany \\ doclerche@web.de \\ Dipl.-Ing. Christian Kehrer \\ ITI GmbH, Schweriner Str. 1, 01067 Dresden, Germany \\ kehrer@itisim.com
}

\begin{abstract}
Increasing energy prices as well as outdated building systems present the housing industry with the challenge of finding new complex system solutions including renewable energy and storage systems. The municipality Lohmen and the local housing association contracted EA Systems and IB Dr. Lerche to develop an integrative energy system concept for its historic town center.

This paper deals with modeling and simulating different energy system variants for the existing building structure using the Modelica-based 'Green Building' library and SimulationX. The discussion illustrates the challenges of the modeling process, innovative solutions and the simulation results.
\end{abstract}

Keywords: Green Building, Building Simulation, Building Quarters, Building Complexes

\section{Introduction}

In Germany, most buildings were erected before any heat insulation regulations existed. Therefore, most of them had to be refurbished from time to time to reduce thermal energy consumption and to adapt to current legislative requirements (e.g. Energy Saving Ordinance).
Especially in the East of Germany, last region-wide refurbishment measures were taken back in the 90s of the last century. Hence, most buildings there still meet current energetic requirements. However, the building energy systems installed at that time have a lifespan of about 20 years. Consequently, building owners today, whether they are private or public, have to think about new refurbishment measures.

Conventional measures to replace existing, outdated heating systems with more efficient system components (e.g. gas-fired condensing boilers) contribute to a significant reduction of energy consumption. But rising energy prices and upcoming legislative requirements to reduce carbon dioxide emissions mean that these measures will not be sufficient. Innovative ideas, like integrating renewable energy systems and storages, have to be tested for applicability to specific building situations.

To meet this challenge, the municipality of Lohmen and the local housing association contracted EA Systems and IB Dr. Lerche to develop an integrative energy system concept for the historic town center. This requires local characteristics, especially the availability of renewable energy, to be scrutinized. In this regard, suitable energy system variants have to be derived and evaluated for energy efficiency, economical requirements and further ecological aspects.

The given complexity requires new analytical methods. The availability of renewable energy has to 


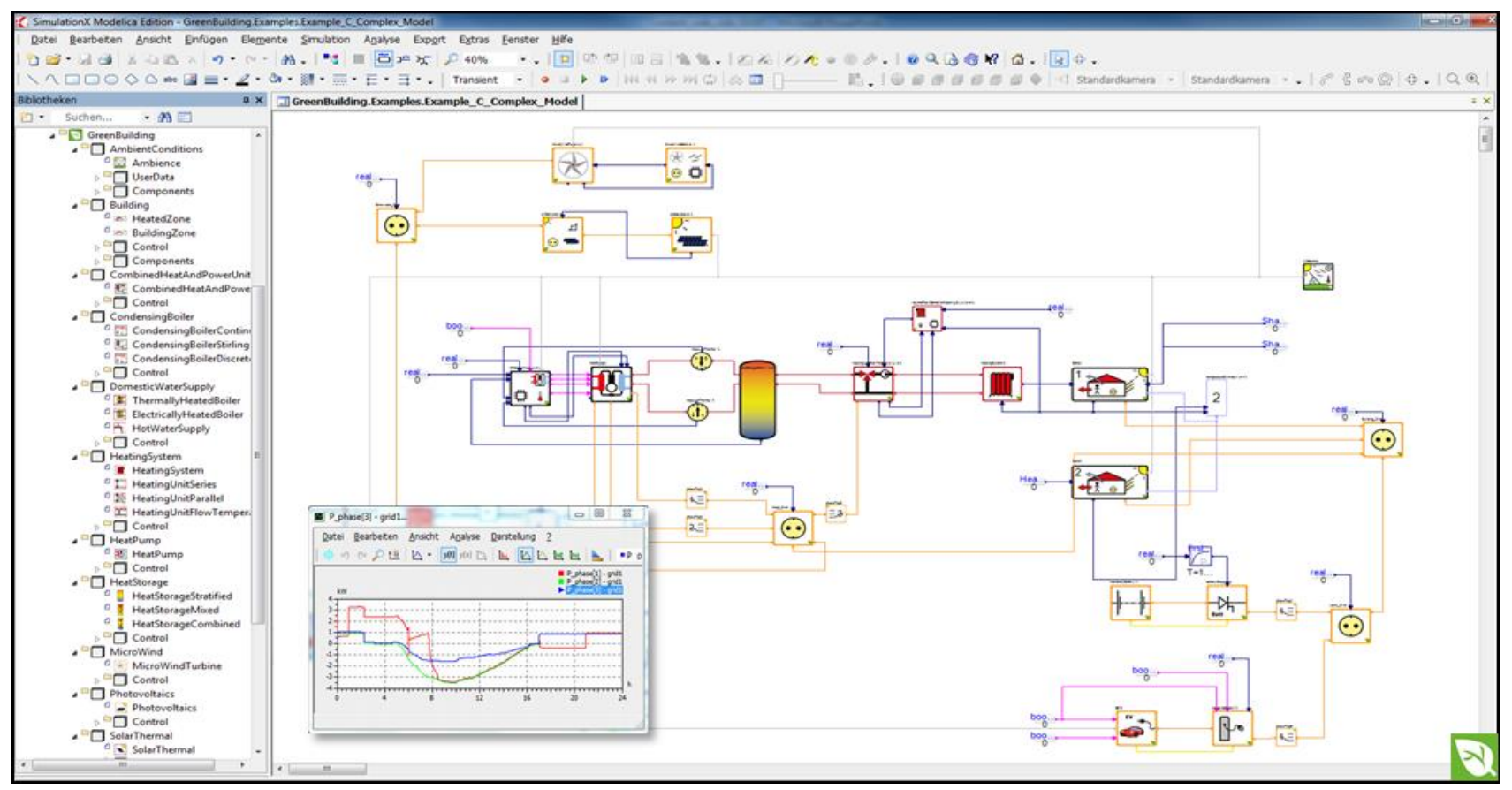

Fig. 1: Modelica model of a renewable energy system incl. the building in the simulation environment

be analyzed in combination with strongly usagedependent energy consumption profiles as well as state-specific applicability of partly new storage systems (e.g. batteries). For that reason, only dynamic simulations of different energy systems can provide sufficient results for an adequate system evaluation.

As a newly developed simulation environment, the Modelica-based 'Green Building' library and SimulationX were used to fulfill the given engineering task. Since it was developed especially for such applications, 'Green Building' can be used to easily model complex energy systems including renewables, storages as well as complex building structures in one simulation environment.

\section{Green Building Simulation Library}

Modelica is an equation-based and cross-domain modeling language. It offers the possibility to model complex building energy systems with different domains (e.g. heat, electricity, control) using differential-algebraic equations. These equation systems can be edited and solved within one simulation environment.

That is why EA Systems used Modelica and the versatile CAE tool SimulationX to develop the 'Green Building' library for the simulation of energy systems [4]. By adapting an approach widely used in the automotive industry, several elements for the production of renewable energy and heating systems were created as well as storages and electrical or thermal consumers [5]. Most of the models represent real world objects like vehicles, electrical inverters or valves. Granularity and complexity of each element are thus in the same range while preserving a flexible yet easy modeling process (i.e. physical as well as phenomenological models [5]). The modeling focus lies on the interactive behavior of different energy system components with varying complexity in the context of building energy supply, be it thermal or electrical (i.e. electrical systems modeled using RMS values [4]). Although the building itself can be modeled as a complex thermal and electrical energy consumer by using a number of thermal zones, a detailed thermal building simulation for different thermal conditions in one room, for example, requires a more specialized tool, like EnergyPlus (Green Building, for example, uses constant average temperatures in thermal zones [5]).

Figure 1 shows the 'Green Building' simulation environment in ITI's SimulationX with a relatively simple model of a single-family home including a heat pump as well as a micro-wind turbine and a photovoltaic system as renewable energy sources [6].

\section{Municipal area of Lohmen}

The surveyed area in the municipality of Lohmen, a small town in the middle of the Free State of Saxony in Germany, includes altogether twelve buildings 


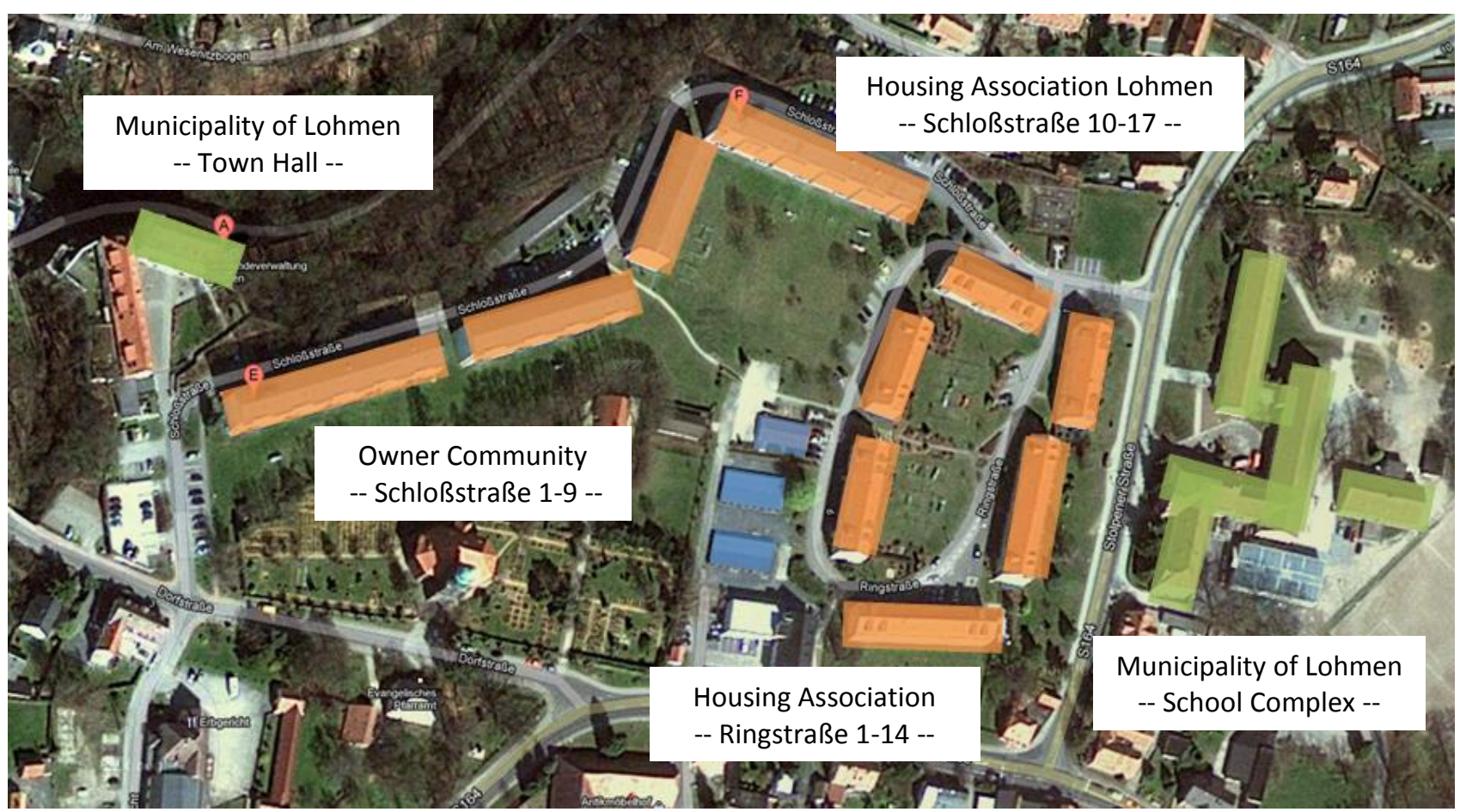

Fig. 2: Historic town center of Lohmen

and building complexes. Besides ten dwelling houses built in the 1960s and 70s, there are also the over 500-year old Lohmen castle, the office of municipality, as well as the school complex with four separate buildings which are part of the study.

Figure 2 shows the historic town center of Lohmen with all acting partners, its municipality, the housing association as well as a local owner community.

Intensive analyzes of available energy saving potentials and existing renewable sources were the basis of the following modeling and simulation work. Initial analyzes dealt with conventional refurbishment measures of existing heating systems and the usage of solar energy. Besides, Lohmen is directly situated at the river Wesenitz with a number of existing water power plants in the area of the historic town center. Hence, further analyzes mainly revolved around the integration of water power as well as water heat usage with heat pumps, for example.

\section{Modeling paradigms and simula- tion results}

Basically, energy can be provided in two ways. Heat and electricity can be supplied to each house individually. That means heat is produced by internal heating systems, like condensing boilers or microcogeneration units. Electricity can be taken from the grid or from locally installed photovoltaic systems on each building's rooftop. These basic approaches are single-building solutions which only replace or modify existing building energy supply concepts. That way, existing renewable energy potentials (e.g. river water heat) cannot be used in an economic way.

Other solutions consider all existing buildings together. These quarters solutions enable an economical use of all available renewable energy potentials as well as existing synergy effects, e.g. electricity production with photovoltaic systems only on rooftops facing South.

Basically, SimulationX' 'Green Building' library was used to implement and to simulate adequate system models. This simulation environment enables the user to simulate variable building energy systems including a building's heating as well as the inhabitants' electricity consumption. The basic modeling idea though was a single-family home. That required some modifications of existing models and the development of new, adequate modeling approaches for the project at hand.

Figure 3 shows two of these newly developed modeling paradigms. The model on the left shows the school complex which consists of four building models for each part of the complex (elementary school, kindergarten, gym, historic school). Each of these building models is implemented as three 'Building Zones' from the 'Green Building' library representing basement, classrooms and roof. Furthermore, the school complex model includes domestic water production, electricity consumption as 

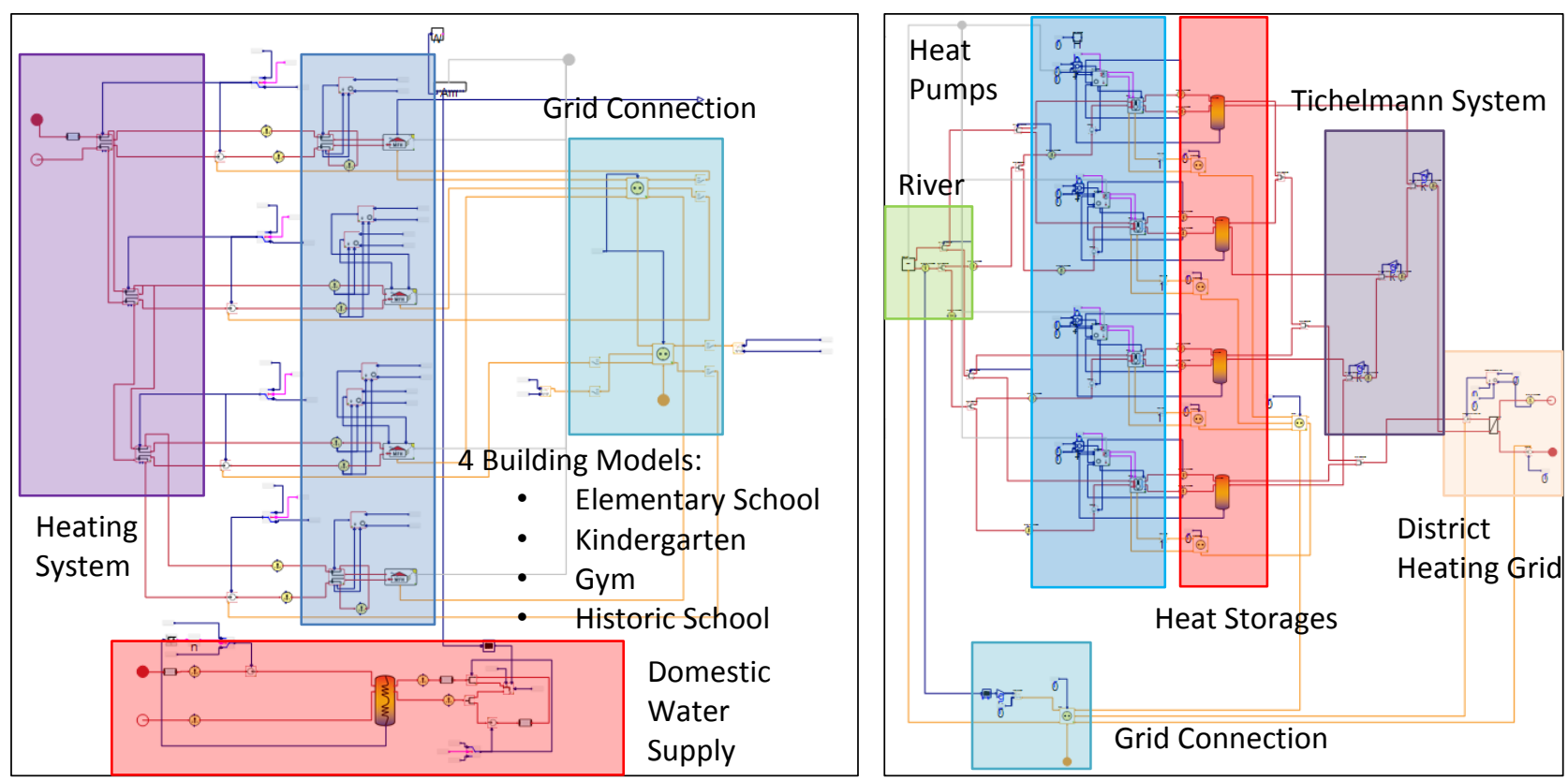

Fig. 3: Sub-model structure of the school complex and the heat pump cascade

well as heating system components (e.g. valves, pipes, etc.).

The right side of figure 3 shows the implemented sub-model of a heat pump cascade to be used as a basic heating system for the quarters. It consists of 'Green Building' heat pump models including connected controllers as well as heat storages. Furthermore, a river model provides information about available water heat and renewable electrical power of existing water power plants. Heat supply to the district heating grid is represented by a convenient heat exchanger model.

Both modeling approaches illustrate the basic modeling idea used during this project. Buildings and usage (domestic water consumption, electricity consumption, etc.) are implemented individually in sub-model components. That way, they can either be used for single-building simulations or for entire quarters simulations without the need for further model adaptations.

\subsection{Single-building simulation}

The following energy system configurations including renewable energy usage were examined in single-building analyzes:

- Condensing boilers

- Micro-cogeneration

- Photovoltaic systems

- Solar thermal collectors

- Gas-fired heat pumps with geothermal energy usage
The replacement of existing condensing boilers always represents a basic strategy to lower natural gas consumption of each building. They are able to provide heat for buildings and domestic water supply at fairly high efficiency rates (higher than 95\%). Adding small micro-cogeneration units to each building's energy system allows for a combined heat and electricity production. That way, general electricity consumption, e.g. for heating pumps and hallway lighting, can be significantly reduced. Especially in Germany, cogeneration units are substantially subsidized by the state. Hence, heat and electricity can be produced at relatively low operating expenses.

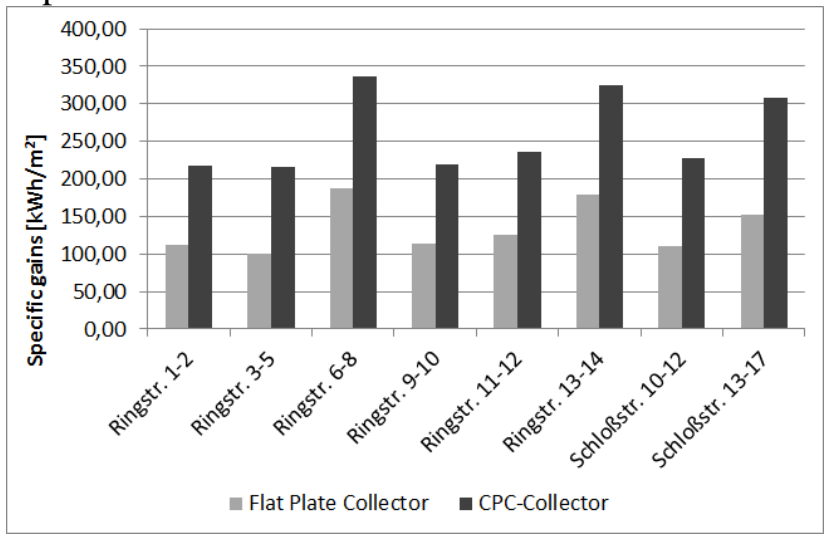

Fig. 4: Specific renewable heat production of different solar collectors at different residential buildings

Photovoltaic systems provide renewable electricity to meet a building's general electricity demand. In Lohmen, general electricity consumption is rather low. Therefore, local electricity production has to 


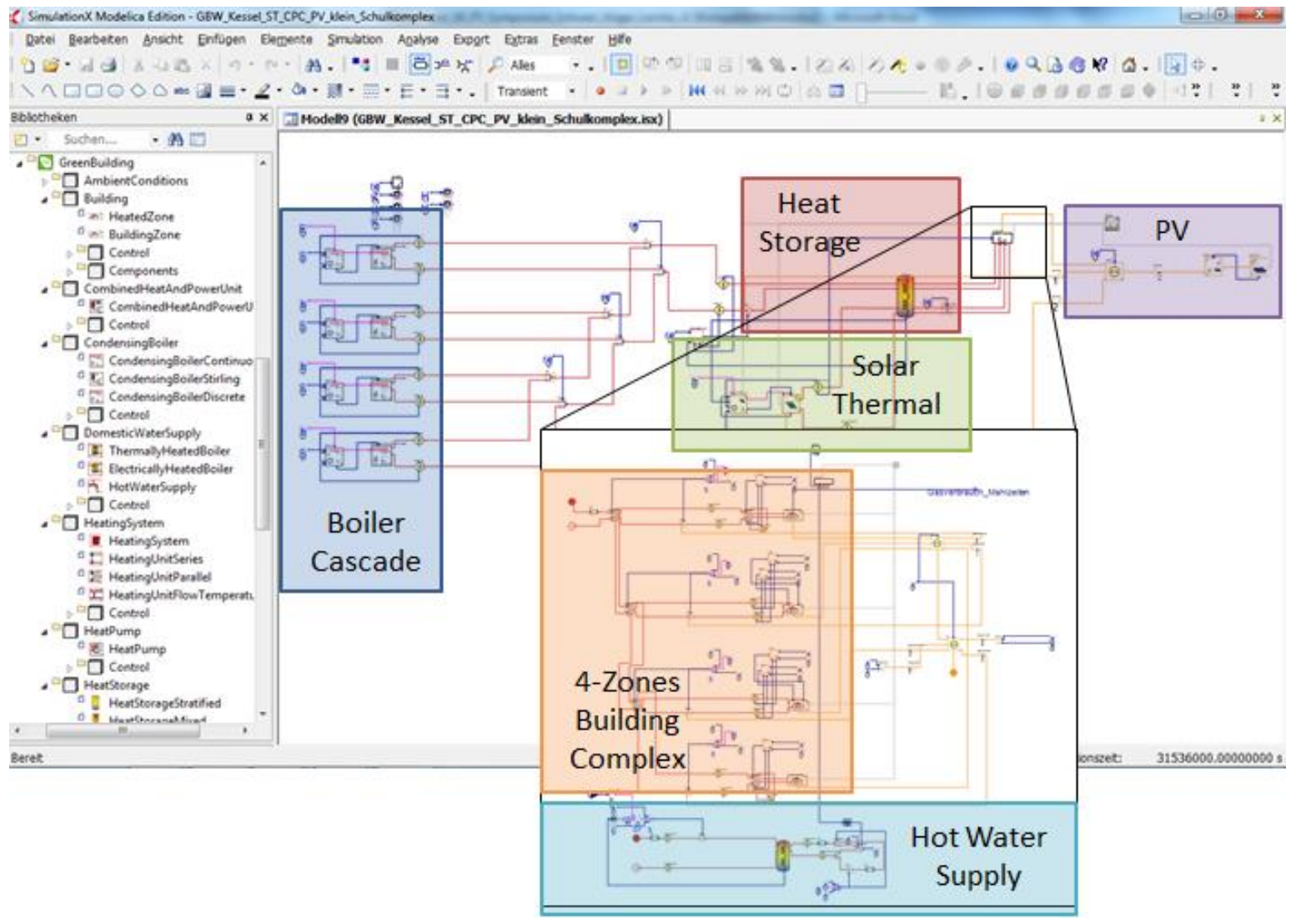

Fig. 5: Single-building model of the school complex with condensing boiler cascade, heat storage, solar thermal collector and photovoltaic system

account for these conditions. The inhabitants' electricity consumption is much higher, but cannot be met easily by local electricity production, because of German tax legislation for housing associations. Furthermore, electricity fed into the grid is not very profitable for newly constructed energy systems. Consequently, the main goal of energy system design is to minimize the amount of electricity fed into the grid while maximizing the production of renewable energy.

Solar thermal collectors constitute another energy system configuration that uses solar energy as a source. They can provide a significant amount of a building's domestic water consumption if they are installed in the right spot (e.g. south facing roofs). However, there are two different types of collectors: flat plate and CPC (Compound Parabolic Concentrator) collectors. Figure 4 shows some sample results from simulation-based analyzes of the solar thermal energy potential of various residential buildings' roofs. CPC collectors always represent a more efficient system variant. Due to quite high system costs, a specific heat gain of at least $250 \mathrm{kWh} / \mathrm{m}^{2}$ is needed on average. Figure 4 shows that only CPC collectors on buildings with south facing roofs (e.g. Schloßstr. 13-17) can provide enough solar energy input for the analyzed system configuration (domestic water production with hot water boilers at $60^{\circ} \mathrm{C}$ ).

The third energy system configuration that was simulated and evaluated for each single building is based on gas-fired heat pumps. Compared to electric heat pumps, these comparatively new systems provide heat using geothermal energy as well as a smaller amount of natural gas.

Figure 5 shows a complete single-building model of the school complex with a condensing boiler cascade as a basic heat supply system, solar thermal collectors to support domestic water supply, and a photovoltaic system to provide renewable electricity. This sample model shows only one of nine simulated and examined system configurations for the school complex:

- Existing building with two 15-year old condensing boilers

- Refurbished energy system (e.g. increased pump efficiency) with some adaptations of the building insulation

- New condensing boiler cascade with modulating working burners

- Condensing boiler cascade with small Stirling CHP

- Condensing boiler cascade with CHP 
- Condensing boiler cascade with solar thermal system (CPC)

- Condensing boiler cascade with CPC collectors and small photovoltaic system

- Condensing boiler cascade with small photovoltaic system

- Condensing boiler cascade with large photovoltaic system

Figure 6 shows results for simulated electricity and natural gas consumptions of the school complex' analyzed system configurations.

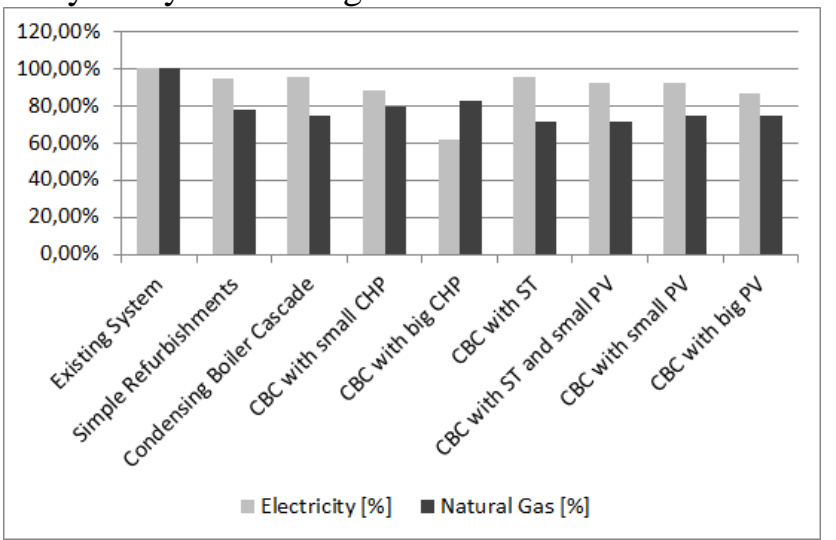

Fig. 6: Simulation results for different system variants of the school complex

All results are compared against the results of an existing old condensing boiler cascade. All variants, except for the existing system, are simulated with simple refurbishments of the building's heat transfer system (e.g. pumps) and the building's insulation. It is evident that even simple refurbishment measures have a significant impact on the heat and electricity consumptions. However, variant 3 with the new condensing boiler cascade is the first energy system variant suitable for long-term decisions due to the age of the existing boiler.

Furthermore, it appears that system variant 5 with a large combined heat and power unit (CHP) could be the most interesting variant regarding energy consumption and system efficiency, because the electricity consumption can be reduced significantly without increasing the natural gas consumption too much.

All in all, over 70 variants of different energy system configurations and different buildings were modeled and simulated using the 'Green Building' library and further presented modeling paradigms. Such energy supply variants for single-buildings, however, have only limited potential to reduce the renewable energy usage and energy consumption. Further analyses have thus been conducted regarding a number of different energy system variants for the entire quarters.

\subsection{Simulation of the Quarters}

The basic idea is to combine all implemented building models (see right part of fig. 3) of ten residential buildings, Lohmen castle and the school complex into one large simulation model plus various energy system configurations. The main part of the heat supply regards a district heating grid implemented with 'Green Building' components. This district heating grid includes volume flows as well as temperature behavior in single pipes to enable dynamic heat loss simulations (i.e. simulated heat losses to ground using a static ground temperature model [7]). The layout of the circulation pump, however, (regarding pressure drops, for example) is configured during preprocessing in order to reduce the number of simulated system states.

Figure 7 shows a sample district heating grid model with several centrally located condensing boiler cascades, a heat pump cascade using river water and water power plants as heat and electricity source as well as two cogeneration units for overall domestic water supply located in the school complex.

Two different types of district heating grids were implemented and analyzed. A "small" district heating grid provides heat from two cogeneration units to meet domestic water requirements of each building. Mechanical space heating is still provided locally by several condensing boiler cascades.

The "large" district heating grid solution includes cogeneration for domestic water supply as well as main heat power production by a $520 \mathrm{~kW}$ heat pump cascade. Heat pumps use river water as environmental heat source and electricity produced at local water power plants as electricity source. Both heat sources are connected to each building via a widespread district heating grid. Further heating power demands are met by smaller peak-power condensing boiler cascades.

Modifications can be done by adding further, smaller photovoltaic systems. Additionally, some of the implemented condensing boilers can be replaced by gas-fired heat pump systems again. That way, the system can be optimized with respect to number and type of the required components.

Such a complex energy system requires sufficient control algorithms to operate the appropriate system components. That way, standby losses of system components that are not in use (e.g. peak power condensing boilers at higher ambient temperatures) can be significantly reduced. Furthermore, renewable energy usage can be increased by avoiding simultaneous heat pump operation, for example. 


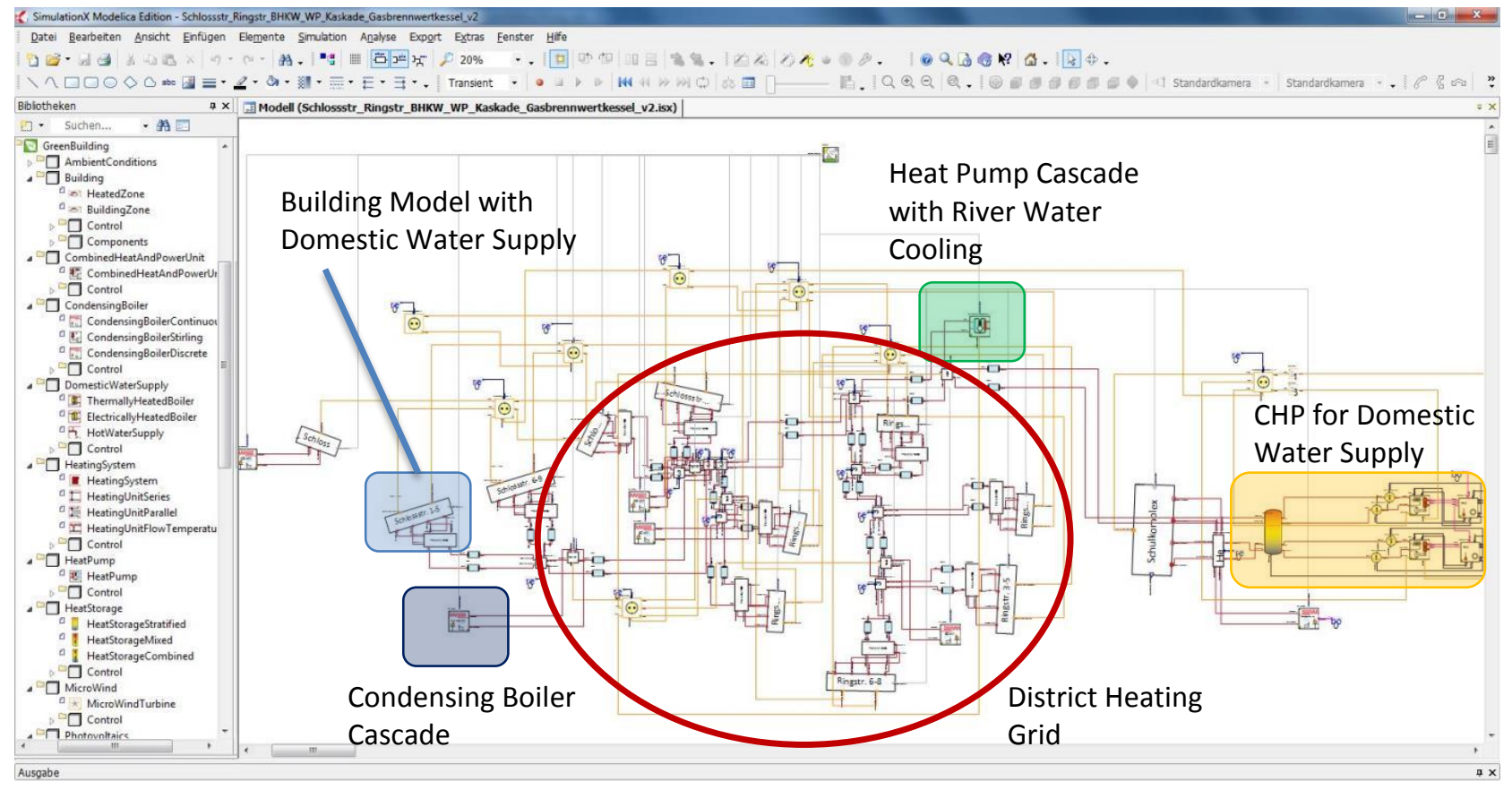

Fig.7: Simulation model of the quarters with district heating grid, micro-cogeneration, heat pump cascade, peak power condensing boiler cascades and all involved building complexes

'Green Building' enables the user to implement physical energy systems as well as corresponding controller behavior (mostly P controllers with hysteresis switch-on/off statements) in one large simulation model within the SimulationX modeling environment. Previously presented optimization tasks can thus be executed more easily.

Each of the two types of energy system configurations for the district heating grids were simulated with four and five different system component configurations and/or control algorithm sets. All results were evaluated in comparison with the buildings' existing energy supply infrastructure and the accumulated results of single building simulations with condensing boilers as the basic heat supply variant.

The simulation's result analysis focused on the affordability of different energy system components. Cost analyses, however, are not a basic part of the 'Green Building' simulation environment. Further result evaluations revealed some interesting aspects regarding energy saving potential as well as overall system sustainability.

Figure 8 shows simulation results for the relative overall energy consumption of each simulated system configuration, divided into natural gas and electricity consumption.

The diagram is divided into three basic parts. The left side shows accumulated results of all analyzed single-building simulations. It illustrates the overall energy consumption of the quarters' existing energy systems, simply refurbished energy systems as well as the basic "energy-concept" regarding the replace- ment of old boiler systems by new condensing boilers.

The second part of the diagram shows results for the previously introduced "small" district heating grid variant. Besides basic system configurations, it was also simulated with a $14.5 \mathrm{kWp}$ photovoltaic system on a suitable building roof. Furthermore, the integration of street lighting into the overall energy system concept was part of some analyses, and some of the integrated condensing boilers were replaced by new gas-fired heat pump systems.

Most simulations for the quarters' analyses were run for a second district heating grid system variant. This "large" variant mentioned earlier includes a heat pump cascade for main heating power supply. It was simulated with and without recognizing street lighting. However, most of the simulated results concern different optimization levels of energy management system.

On the one hand, basic energy management system algorithms forced the CHP cascade to provide heat for domestic water supply in residential buildings even in winter months when sufficient heat power is directly needed in the school complex. On the other hand, all peak power condensing boilers stay activated even in case of ambient temperature levels above the estimated bivalence point. Furthermore, all heating systems, even the heat pump cascade, are operated at comparatively high flow temperature levels.

Evidently, the system does not work in an optimal way. Therefore, some optimization steps were taken 


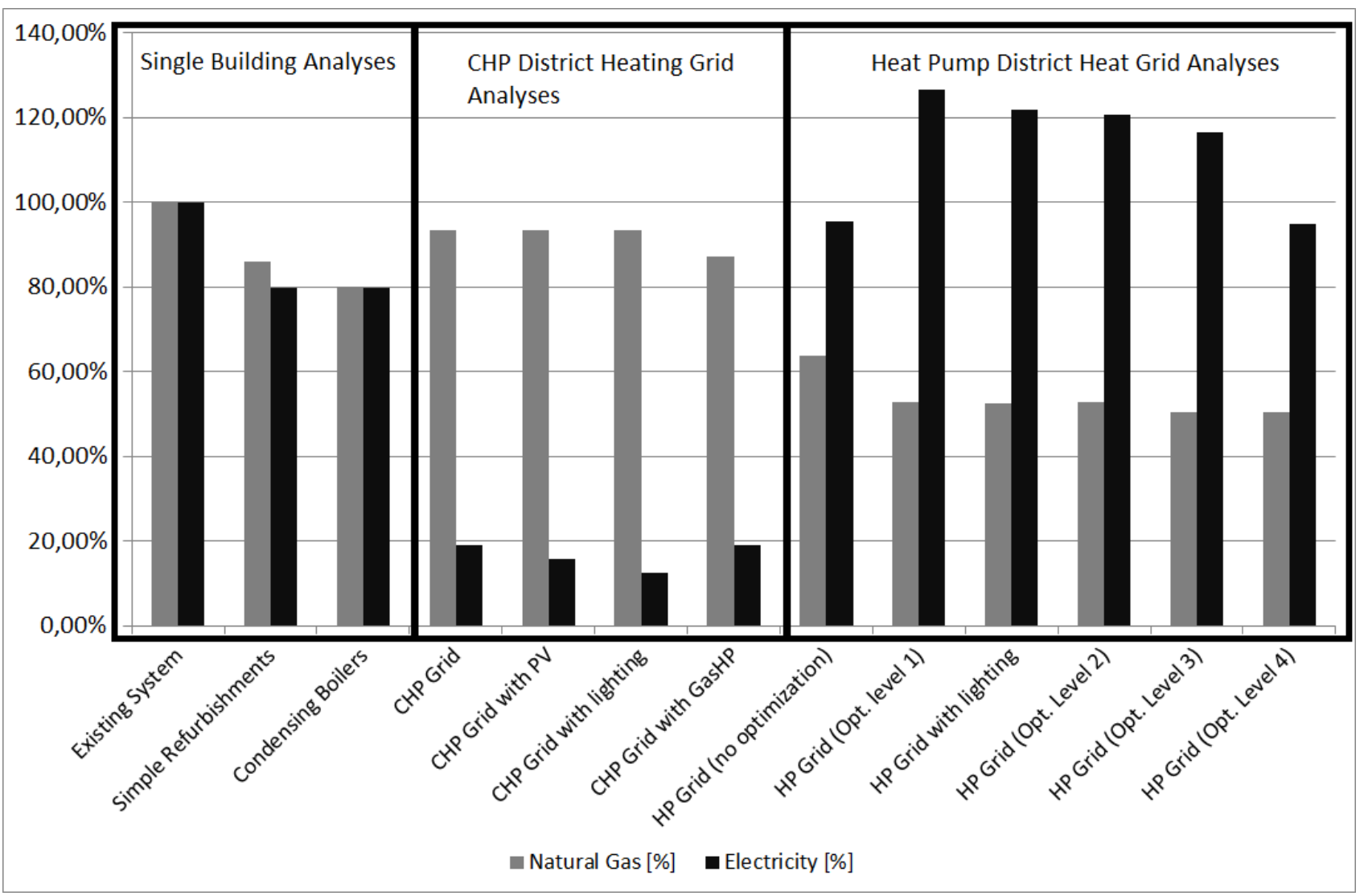

Fig.8: Simulation results of different energy system variants for complete quarters solutions

to improve the implemented energy management algorithms. First of all, the condensing boiler cascades were shut down in case of ambient temperature levels rise above the bivalence point. Furthermore, the CHPs are only used to provide residential buildings with domestic water in transitory and summer periods. These measures are shown as optimization level 1 in figure 8.

Optimization level 2 refers to the reduced operation of the heat pump system during the summer months. Heat pump systems are supposed to provide heat only to connected buildings. However, they are not intended to provide domestic water because of required higher temperature levels. Lowering the heat pump cascade thus reduces standby losses without affecting any heat power needs.

The third optimization level refers to reductions of preconfigured reference temperatures for all implemented heating system components (i.e. heat pump cascades, peak-power condensing boilers). That way, reference temperatures could be reduced by about $5 \mathrm{~K}$ to enable all components to run in better working ranges (e.g. COP of heat pumps).

The last optimization level affected only switchon and switch-off times of the planned heat pump cascade. In the planned "large" district heating grid system variant, all heat pumps are equally used to provide heat (c.f. Tichelmann system in fig. 3). All previously presented energy management algorithms forced each heat pump to work mainly at the same time (i.e. control hysteresis was implemented in the same way). Hence, this control regime was adapted to sequentially drive the heat pump cascade. This way, electricity provided by the water power plant can be used more efficiently to power each heat pump. That enabled a reduction of the overall electricity consumption.

Both variants of district heating grids offer massive reductions of energy consumption and a better use of available renewable energy. The "small" district heating grid variant provides huge reductions of electricity (ca. 80\%) consumption even in comparison to refurbished single-building system variants. This is mainly caused by comparatively huge amounts of electricity produced by the CHP system. However, the overall natural gas consumption increases slightly because of partly simultaneous heat and electricity production.

The "large" district heating grid shows opposite results. Using environmental energy as well as electricity to provide heat massively decreases the natural gas consumption (ca. 50\%). However, existing power plants cannot generate all electricity required for the heat pumps' operation. Hence, the overall 


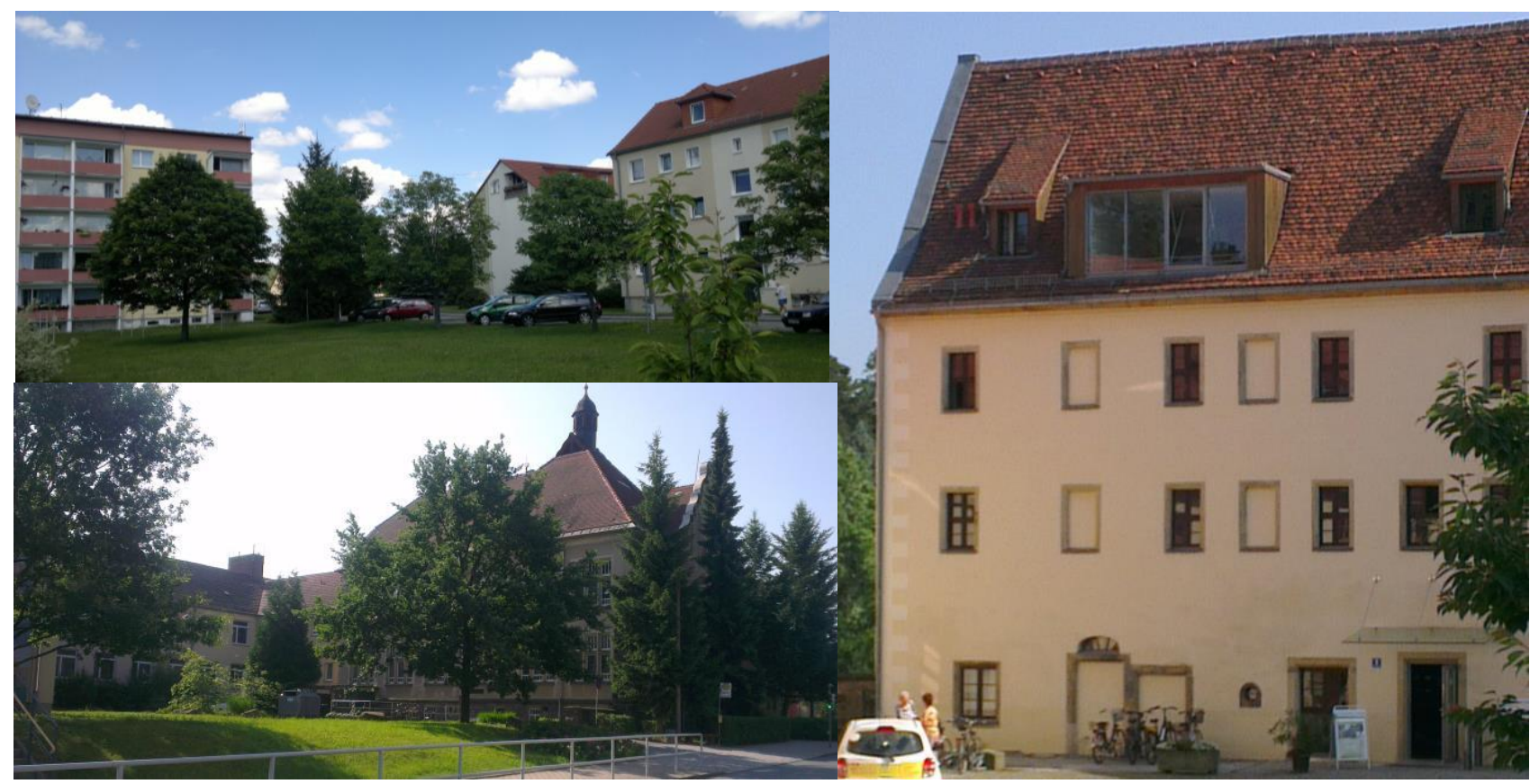

Fig.9: Pictures of residential buildings (top left), historic school (bottom left) and ancient Lohmen castle (right)

electricity consumption can even exceed the existing electricity demand. Apparently, system optimization as well as iterative improvements of implemented energy management algorithms can sufficiently decrease these effects.

Finally, both district heating grid solutions provide extensive reductions of energy consumption. This is mainly achieved by using huge amounts of renewable, environmental energy (e.g. water power) as well as synergies in the existing quarters. That way, providing electricity, which is produced by a newly installed CHP system, to street lighting would further decrease overall electricity consumption in a significant way.

Furthermore, replacing some of the additionally needed peak-power condensing boilers by an adequate number of gas-fired heat pumps using geothermal energy as additional heat source can significantly improve natural gas consumption as well.

\section{Conclusions}

This paper shows how the SimulationX 'Green Building' library was used to analyze and to evaluate different suitable building energy system variants of building quarters in the historic town center of Lohmen. Some selected modeling paradigms are presented to demonstrate how to use 'Green Building' for simulating larger building complexes.

Furthermore, the developed analyses approach, be it the comparison of different energy system configu- rations for single buildings or the evaluation of the given quarters as one unit, is presented as well.

Some simulation results are illustrated for one single building evaluation process regarding the school complex. In comparison to that, both developed energy system variants representing a district heating grid are introduced with their specific characteristics. Simulation results are evaluated in comparison to single-building analyses. Advantages and disadvantages of both variants and derived system configurations are discussed at the end.

The simulation models are relatively complex. The simulation of a single building energy system took 0.5 to 4 hours for one year. In comparison to that, simulations of the quarters took between 3 and 4 days to finish. It is thus evident that 'Green Building' can be used to economically analyze complex variants of building energy systems. Parallelization by using multi-core computing can further improve this aspect.

Extensive engineering efforts yielded a comparatively high numerical stability of the Green Building library [6]. That way, simulating even complex, coupled numerical systems (linear and nonlinear) does not affect convergence. The presented project, for instance, comprised complex quarter models with up to 3000 system states. Simulating these models for one year causes around one million event iterations.

The presented results are part of a research study which is funded by KFW (Development Load Corporation) and communal as well as private investors. The complete research project includes theoretical, 
simulation-based analyses of sufficient energy system configurations. First approaches as well as initial simulation results were also shown in [3]. Acting partners (c.f. fig. 2) can decide which energy system variant meets their predefined requirements best with respect to affordability and sustainability. The chosen energy system variant will be built in a second project part beginning in the middle of 2014.

\section{References}

[1] Schwan, T., Unger, R., Lerche, Dr.-Ing. C.: 1. Zwischenbericht - Erstellung eines integrativen Quartierskonzepts für das Quartier Schloß- und Ringstraße in Lohmen. EA Systems Dresden GmbH, June, 2013.

[2] Unger, R.; Schwan, T.; Mikoleit, B.; Bäker, B.: Bessere regenerative Energieversorgung für Quartiere und Gemeinden durch systemübergreifende Simulation, 5. Internationaler Kongress Bauhaus SOLAR, Erfurt, 13./14. November 2012.

[3] Schwan, T., Unger, R., Lerche, Dr.-Ing. C.: Model-Based Design of Integrative Energy Concepts for Municipalities, 16th ITI Symposium, Dresden, 12./13. November 2013.

[4] Schwan, T., Unger, R., Baeker, B., Mikoleit, B., Kehrer, C.: Optimization-Tool for local renewable energy usage in the connected system: Building-eMobility; 8th International Modelica Conference, Dresden, 20.-22. March 2011.

[5] Schwan, T., Unger, R., Baeker, B., Mikoleit, B., Kehrer, C.: Optimization of local renewable energy systems using automotive simulation approaches, 12th Conference of International Building Performance Simulation Association, Sydney, 14.-16. November 2011.

[6] Schwan, T., Unger, R., Bäker, B., Mikoleit, B., Kehrer, C., Rodemann, T.: "Green Building" - Modelling renewable building energy systems and electric mobility concepts using Modelica, 9th International Modelica Conference, München, 03.-05. September 2012.

[7] K.-H. Dahlem, H. Heinrich: Einfluss des Grundwassers auf den Wärmeverlust beheizter Keller. 10. Bauklimatisches Symposium, Dresden, 1999. 